\title{
Gestation and Oral Health: Insinuations on Pregnancy Outcome and Infant Health - A Review Article
}

\author{
Dr Rajalakshmi. G \\ Research Scholar, Amrita Vishwa Vidyapeetham, Amrita Institute of Medical Sciences, Kochi, Kerala, India \\ *Corresponding Author: Dr Rajalakshmi. G, Research Scholar, Amrita Vishwa Vidyapeetham, Amrita \\ Institute of Medical Sciences, Kochi, Kerala, India.
}

\begin{abstract}
Gravidity is a phase of epic ecstasy with exhilaration and there is no boosted feeling for a woman than the movement of life in her. It is also a vibrant physiological state which is evidenced by several transient changes like, nausea, fatigue missed periods, tender swollen breasts, the changes causing the deterioration of oral hygiene. Hormonal changes, nausea, vomiting and malnutrition are among the factors create a favourable environment to deteriorate oral and dental health. Periodontal diseases have their negative implications both for the overall health status of the conceived woman and the foetus. Though the importance of oral care in pregnancy was known from decades, still the practice of maintaining good oral health before conception is less in developing countries like India. This is a modest effort to state the importance of dental health care in pregnancy for prenatal and infant oral health care.
\end{abstract}

Keywords: Gravidity, Periodontal, Physiological, Prenatal, Oral

\section{INTRODUCTION}

Mouth is an apparent portico of microorganisms and is deliberated as the mirror of body and mind. Oral health of the mother has substantial inferences for birth outcomes and health of new born [1]. Scientific evidences suggest that maternal oral flora is diffused to the newborn infant, and cariogenic flora in the mother predisposes the infant to the dental caries [2]. The gale of hormones which is persuaded during pregnancy causes variations in the mother's body and the oral cavity. Pregnancy gingivitis (60 to $70 \%$ ) is one of the most common problem associated with pregnancy [3].The other oral changes seen in pregnancy include gingival hyperplasia, pyogenic granuloma and salivary changes. Facial pigmentation is also increased with pregnancy [3].

Higher levels of the circulating oestrogen causes an increased capillary permeability and prompt to gingivitis and gingival hyperplasia in pregnancy [4]. Marginal gingiva and the interdental papilla are mainly associated with pregnancy gingivitis and is also related to the pre-existing gingivitis [5]. Gingivitis is an inflammation of the gums due to accumulation of plaque between the gums and the teeth leading to bone loss around the teeth and can eventually cause decay and loss [6-7]. Good oral hygiene prevents or reduce the severity of the hormone mediated inflammatory oral changes.

Maternal periodontal disease is another chronic infection of the gingiva and supporting tooth structures that cause preterm birth, preeclampsia etc [8]. Preterm birth gestation, occursis the leading cause of neonatal morbidity and mortality in non-anomalous infants [9]. Periodontal disease is an inflammatory condition caused by gram-negative anaerobic infection of these structures [9]. Gingival crevicular fluid contains inflammatory mediators and oral pathogens related with periodontal disease. The direct tissue damage resulting from plaque and indirect damage through bacterial induction, inflammatory and immune responses of host may be responsible for the pathogenesis of disease [9].

Dental caries is another common problem seen in pregnancy and is a pathologic process of teeth "decay" and formation of "cavity". Due to acid production at the tooth surface by cariogenic bacteria in dental plaque, dietary carbohydrates get metabolized leading to caries formation [1]. These cariogenic bacteria, false dietary practices, use of fluorides that dampen the caries process etc may further accelerate the process [11]. Mother's oral flora may get transmitted and increased maternal cariogenic flora 
predisposes the infant to the development of caries [10].

Pyogenic granulomas (pregnancy tumors) occur in about $1 \%$ to $5 \%$ of the pregnant women, occurs mainly on the labial aspect of the interdental papilla [12]. It is most common in the first pregnancies, during the first and the second trimesters and it may relapse after the child's birth. Though rare it may cause tooth mobility, probably results from the changes in the lamina dura, attachment apparatus, or from the underlying pathology [12].

Morning sickness usually seen in $1^{\text {st }}$ trimester associated with nausea and vomiting due to increased gonadotropins. The gastric acids so produced may erode the enamel on the inner surface of the teeth, most commonly the front teeth. Erosion of the enamel can be controlled by rinsing mouths thoroughly after vomiting, with a solution that contains sodium bicarbonate [13]. Sodium bicarbonate neutralizes the acids and it prevents the damage which is caused by the residue which remains on the teeth [14].

Dental treatments are not advised in all three trimesters of pregnancy [15]. During the first trimester, it is suggested that patients be assessed for existing dental health and dental procedures are not usually recommended. Dental treatment confined to a periodontal prophylaxis and emergency treatments [16]. Routine radiographs should be strictly avoided, as it may hamper organogenesis, affects the developing embryo and even can cause spontaneous abortions. By the second trimester, the organogenesis is complete, and the risk to the foetus is low. Controlling the active lesions, scaling and other elective procedures may be performed with the opinion of concerned obstetrician [17].

During $3^{\text {rd }}$ trimester, foetal growth continues and is a risk to the upcoming labour process and the safety of the pregnant woman [17]. The chair positioning is highly important if the pregnant woman is positioned supine for the procedures, the weight of the gravid uterus may cause a condition which is called supine hypotension. This situation is easily remedied by a proper positioning of the patient on her left side and elevating the head of the chair, to avoid compression of the major blood vessels. Medications that affect the bleeding time to be avoided in the early part of the $3^{\text {rd }}$ trimester routine dental treatment may be performed but not from the middle of the $3^{\text {rd }}$ trimester [18-19].
Medications should be minimal, safe and drug dose adjustments may be indispensable. There are certain drugs proven to cause teratogenesis to be excluded like carbamazepine, aminopterin, androgens, angiotensin converting enzyme (ACE) inhibitors, busulfan, chlorobiphenyls, cyclophosphamide, diethylstilbesterol, etretinate, isotretinoin, lithium, methi-mazole, pencillamine, phenytoin, tetracycline, trimethadione, valproic aciddanazol, etc

\section{CONClusion}

It is enthralling to deliberate preconception oral health treatment can mend women's health, pregnancy outcomes, and infant health .Regardless of the potential for better oral health and pregnancy outcomes, public policies that support comprehensive dental services in India are not in par with the developed nations. Awareness to be created among women and their health care providers about the importance of oral health. Public health care system must promote an understanding among all woman of child bearing ages about the importance of oral health before and after conception and increase their ability to impedeavertible oral diseases

\section{BIBLIOGRAPHY}

[1] Oral Health in Women During Preconception and Pregnancy: Implications for Birth Outcomes and Infant Oral Health Kim A. Boggess - Burton L. Edelstein Springer Science+Business Media, Matern Child Health J (2006) 10:S169-S174

[2] Tracy M Dellinger H. Mark Livingston. Pregnancy: Physiological changes and considerations for dental patients. Dent Clin N Am. 2006;50:677-97.

[3] Lakshman Suresh, Lida Radfar. Pregnancy and lactation. Oral Surg Oral Med Oral Pathol. Oral Radiol Endod. 2004;97:672-82.

[4] Ferris GM (1993) Alteration in female sex hormones: their effect on oral tissues and dental treatment. Compendium 14(12): 1558-1564.

[5] Silk H, Douglass AB, Douglass JM, Silk L. Oral health during pregnancy. AM Fam physician. 2008;77:1139-44.

[6] Soory M. Hormonal factors in periodontal disease. Dent Update. 2000; 27:380-83.

[7] Gajendra S, Kumar JV. Oral health and pregnancy: A review. N Y State Dent J. 2004;70:40-44.

[8] Boggess KA, Lieff S, Murtha AP, Moss K, Beck J, et al. (2003) Maternal periodontal disease is associated with an increased risk for preeclampsia. Obstet Gynecol 101(2): 227-231. 
[9] Agueda A, Echeverria A, Manau C. Association between periodontitis in pregnancy and preterm or low birth weight: Review of the literature. 2008;13:E609-15

[10] Kohler B, Andreen I, Jonsson B. The effect of caries-preventive measures in mothers on dental caries and the oral presence of the bacteria Streptococcus mutans and lactobacilli in their children. Arch Oral Biol. 1984;29:87983.

[11] Rakchanok N, Amporn D, Yoshida Y, Rashıd HO, Sakamoto J (2010) Dental caries and gingivitis among pregnant and non-pregnant women in Chiang Mai, Thailand. Nagoya J Med Sci 72(1-2): 43-50.

[12] Yuan K, Wing LY, Lin MT. Pathogenetic roles of angiogenic factors in pyogenic granulomas in pregnancy are modulated by female sexhormones. J Periodontol. 2002;73:701-08.

[13] Koch KL, Gastrointestinal factors in nausea and vomiting of pregnancy. Gastroenterol Clin N Am. 2003;32:201-34.
[14] Richter JE. Gastroesophageal reflux disease during pregnancy. Gastroenterol Clin N Am. 2003; 32:235-61]

[15] Richards AG. Dental X-ray protection. Dent Clin North Am. 1968;631-41.

[16] Capasso F, La Penna C, Carcione P, Vestri A, Polimeni A, Ottolenghi L. Oral health and pregnancy Ann Lg. 2011;23(2):137-45

[17] Nayak AG, Denny Veena KM. Oral health care considerations for the pregnant woman. Dent update. 2012;39(1):51-54

[18] Singh M. The pregnant dental patient. J Mass Dent Soc. 2012;60(4):32-34

[19] Kandan PM, Menaga V, Kumar RR. Oral health in pregnancy (guidelines to gynaecologists, general physicians and oral health care providers. J Pak Med Assoc. 2011;61(10):1009-14.

Citation: Dr Rajalakshmi. G. Gestation and Oral Health: Insinuations on Pregnancy Outcome and Infant Health - A Review Article. ARC Journal of Dental Science. 2020; 5(3):14-16. DOI: https://doi.org/10.20431/ 2456-0030.0503004.

Copyright: (c) 2020 Authors. This is an open-access article distributed under the terms of the Creative Commons Attribution License, which permits unrestricted use, distribution, and reproduction in any medium, provided the original author and source are credited. 